\title{
UNAS REDONDILLAS INÉDITAS SOBRE FERNÁN GONZÁLEZ: LA TRANSMISIÓN DE LA LEYENDA ARLANTINA POR EL CAUCE DE LA TRADICIÓN
}

\author{
Alberto Escalante Varona \\ Universidad de Extremadura \\ albertoev@unex.es
}

\begin{abstract}
RESUMEN: En este articulo proponemos un estudio acerca de un conjunto de coplas reproducidas originalmente en una serie perdida de pinturas arlantinas sobre el conde Fernán González. Se transcribe el contenido de estas coplas, atendiendo a los testimonios conservados sobre su existencia. Se relaciona el contenido de las mismas con el estado de configuración de la leyenda en los siglos XV y XVI. Finalmente, se reflexiona sobre el concepto de "tradición" y su configuración en múltiples canales de transmisión -literaria, artística, historiográfica, etc.-, aplicado a la pervivencia de esta leyenda castellana en diferentes formatos.

PALABRAS CLAVE: Monasterio de San Pedro de Arlanza, argumento tradicional, fray Gonzalo de Arredondo, crónica, retablo, polémica historiográfica.
\end{abstract}

\section{SOME INEDIT STANZAS ABOUT FERNÁN GONZÁLEZ: THE TRANSMISSION OF THE LEGEND FROM ARLANZA BASED IN THE TRADITION}

\begin{abstract}
In this paper we propose a study about some stanzas about the count Fernán González, expressed originally on some paintings from the Monastery of Arlanza, now lost. We reproduce those stanzas, as they were transcribed in some late testimonies. We stablish relations between them and the literary configuration of the legend of the count in the $X V^{\text {th }}$ and $X V I^{\text {th }}$ centuries. Finally, from a reflection of the multiplicity of "tradition" as a concept -in its literary, artistic and historic aspects-, we apply our conclusions to those paintings, in order to study the transmission of the legend in different formats.

KEYWORDS: Monastery of San Pedro de Arlanza, traditional story, brother Gonzalo de Arredondo, chronicle, retable, historiographic polemic.
\end{abstract}

Recibido: 02/11/2017. Aceptado: 02/02/2018 


\section{Introducción}

El patrimonio artístico y literario creado en el monasterio de Arlanza, en relación con la leyenda de Fernán González y sus milagrosas victorias contra el enemigo musulmán, constituye una de las fuentes principales para el estudio de la historia medieval de Castilla. No obstante, la dispersión y pérdida de muchos de sus fondos pictóricos, escultóricos y documentales, debido a diversos azares sociales y políticos, ha dificultado en buena medida toda aproximación crítica a uno de los principales centros de producción y reinterpretación de la tradición hispánica. Por tanto, esta circunstancia condiciona la metodología de estudio sobre la producción cultural arlantina: toda propuesta de reconstrucción de archivos, bibliotecas y fondos artísticos del monasterio que se ha realizado en los últimos años ha partido de un rastreo no solo de los ítems conservados, sino también de referencias a aquellos que o bien se perdieron, o bien no han sido aún localizados.

En ese sentido, en el presente trabajo presentamos la recuperación de unos textos sobre la leyenda de Fernán González, en relación con la fundación del monasterio ligada a las victorias del conde en su guerra contra Almanzor. Se trata de una serie de coplas que aparecerían pintadas sobre las tablas de un retablo en el que se plasmarían las principales escenas de este relato. Proponemos la reconstrucción de estos textos y sus correspondientes pinturas, a través de diversos testimonios datados desde finales del siglo XV hasta mediados del XIX. Encuadraremos los contenidos pictóricos y lingüísticos de este retablo con la narración sobre el conde elaborada en el monasterio, así como la configuración literaria del personaje en la producción cronística tardomedieval. Por último, relacionaremos el contenido de estos textos con la tradición arlantina, manifestada en un complejo entramado de códigos pictóricos, literarios y arqueológicos en los que los significados religiosos e identitarios sobre el origen legendario de Castilla se actualizan constantemente a través de la recepción popular.

\section{Estado de la cuestión: la figura de Fernán González en los siglos XV y XVI}

El estudio de la figura de Fernán González en la literatura española, desde la Edad Media hasta la actualidad, no cesa de arrojar nuevos resultados ${ }^{1}$. No

1. En este sentido, la antología de Correa Calderón (1964) supone la primera catalogación detallada y completa de textos sobre el tema. Cotrait $(1969,1970,1973 a, 1973 b)$ amplía el listado con textos de los siglos XVII y XVIII. Estos resultados son posteriormente revisados por Pérez Priego (1989) y 
obstante, en lo referente al periodo renacentista aún no se ha realizado una exhaustiva revisión bibliográfica. Ello plantea un serio problema en el análisis de la transmisión de la leyenda a través de textos que bien pudieron ser fuente para la composición de las primeras comedias barrocas sobre el conde castellano, ya en el primer tercio del siglo XVII. Igualmente, supondrían interesantes manifestaciones del estado de elaboración del relato en los canales historiográficos del momento.

En ese sentido, a día de hoy, el corpus elaborado localiza dos vías de transmisión de la leyenda en esta centuria. Por una parte, en crónicas; por otra, composiciones poéticas, principalmente el Romancero nuevo. Procederemos a continuación a listar las principales contribuciones en el primer campo: las crónicas arlantinas y las crónicas populares.

A finales del siglo XV, fray Gonzalo de Arredondo, abad de Arlanza, compone tres crónicas sobre Fernán González ${ }^{2}$. La transmisión textual de estas obras es compleja y en ella intervienen diversos factores: la voluntad propagandística que realiza el abad hacia su propio monasterio; la configuración del conde como mito fundacional de Castilla, para legitimar los linajes regios de los Reyes Católicos y Carlos V (Gómez Pérez 1959); y la voluntad predicadora del autor, que concibe su manuscrito como medio de transmisión de relatos de buenas obras y lecciones santas que servirían para enseñar a los fieles.

Frente a estas monumentales crónicas, que nunca se llegaron a imprimir (aunque al menos una de ellas se compuso para ese fin; Vaquero 2003), nos encontramos con una larga lista de crónicas populares, en formato de 4, que se imprimen desde 1511 hasta mediados del siglo XVIII. En estos textos anónimos se reducen los contenidos fundamentales de la leyenda, casi siempre en relación con otros temas épicos (principalmente, el martirio de los Siete Infantes de Salas), focalizando la narración en la descripción de las hazañas bélicas. Su configuración textual atiende a los códigos editoriales del género

Grande Quejigo (1991), si bien centrándose en la época medieval. En la última actualización, publicada en el Boletín de la Institución Fernán González (Escalante Varona 2016), se recuperan nuevos textos desde la Edad Media hasta el siglo XIX.

2. La Crónica arlantina de los famosos y grandes hechos de los bienaventurados sanctos cavalleros conde Fernand Gonzales y Cid Ruy Dies [...], conservada en un "extracto-manuscrito" de 1755; la Corónica brevemente sacada de los excelentísimos fechos del bienaventurado caballero de gloriosa memoria conde Fernán Gonçales [...], compuesta entre 1492 y 1504; y la Chrónica de los ermosos fechos y exemplos del excellentisimo y fuerte cavallero conde don Ferán González, compuesto entre 1502 y 1526. Véase el completo estudio de Vaquero (1987) sobre esta cuestión, en el que realiza un minucioso recorrido por las diferentes manifestaciones documentales de las tres obras y establece pautas para su colación. Toscano $(1980,1981 \mathrm{a}, 1981 \mathrm{~b}, 1982)$ edita fragmentos de algunos de los testimonios conservados. Aún está pendiente su edición crítica. 
caballeresco, si bien el relato del conde contenido en ellas no responde a los rasgos de configuración del género literario propiamente dicho ${ }^{3}$.

No debemos confundir estas crónicas con la denominada Historia arlantina: se trata de un texto de mayor extensión, procedente de un manuscrito originalmente conservado en el monasterio de Arlanza, y copiado o elaborado por el bachiller clérigo García Moreno en 1492. Dicho manuscrito, hoy en día en manos de un anónimo particular (Gómez Pérez 1959: 566-567), contó con dos ediciones impresas, en 1537 y 1546; se transmitió también en dos copias manuscritas de los siglos XVII y XVIII. Esta crónica consiste, según Menéndez Pidal (1896: 397), en una refundición de la Crónica Geral de 1344, y pudo tratarse de una de las fuentes empleadas por Arredondo para la redacción de sus obras.

La existencia de estas crónicas plantea a su vez dos canales de recepción y configuración de la leyenda atendiendo al público lector: las crónicas monásticas, además de servir como medio propagandístico, plantean una vía genealógica de la que ya tenemos antecedentes en la literatura sapiencial, varias semblanzas y diversas crónicas particulares del Medievo ${ }^{4}$. Fernán González aparece en ellas como legitimador de linajes, dechado de buenas virtudes para el gobernante. Algunos de estos textos son coetáneos a la moda de la literatura caballeresca, que configura la segunda forma de recepción de la leyenda de Fernán González: las mencionadas crónicas populares, mucho más baratas y manejables, que gozan de un gran éxito (que propicia sus continuas reimpresiones) y se centran exclusivamente en los pasajes más espectaculares y sentimentales de la vida del conde, antes que en sus virtudes santas. Las crónicas de Arredondo, por ejemplo, participan de ambas vías: el abad vive inmerso en un mercado editorial que prima la impresión de las crónicas breves o relatos caballerescos propiamente dichos. Ello determina el fracaso de Arredondo en su empeño por imprimir su obra, pese a que introdujo en ella elementos novelescos para tal vez atraer la atención del público lector, ávido de historias caballerescas 5 .

3. Vaquero (2003) estudia la trayectoria editorial de estas crónicas en relación con las obras manuscritas de Arredondo. Corfis (2011) edita la editio princeps de estas crónicas, de 1511. Véase también el capítulo dedicado a ellas en el volumen IV de la Historia de la prosa medieval castellana, de Gómez Redondo (2007).

4. Véanse, por ejemplo, los exempla XVI y XXXVII del Conde Lucanor; los Loores de los claros varones de Castilla, de Fernán Pérez de Guzmán; Las bienandanzas e fortunas, de Lope García de Salazar; la Atalaya de las crónicas, del Arcipreste de Talavera; o El Victorial de Gutierre Díez de Games, donde Fernán González aparece junto al (o "a El”) Cid y Fernando III como uno de los héroes capitales de la cristiandad junto a otros héroes judeocristianos, a modo de actualización de los Nueve de la Fama.

5. El estudio de estas crónicas a lo largo de los siglos XVI, XVII y XVIII, atendiendo a las reformulaciones que plantean sobre los episodios de la leyenda, aún está pendiente. Los resultados que se 


\section{Un nuevo ejemplo de transmisión artística y literaria: las tablas del monasterio de Arlanza}

Al estado de la cuestión sobre la leyenda del conde en la literatura moderna, tenemos que añadir una composición recientemente redescubierta ${ }^{6}$, que constituye una manifestación literario-artística nueva en una forma de transmisión arlantina de la leyenda en la que la crítica aún no había reparado.

Se trata de unas coplas en las que se desarrollan episodios clave de la vida de Fernán González, en su versión arlantina. Están recogidas en un legajo de papeles manuscritos localizado en la BNE7 . El legajo data del siglo XVIII. Son materiales recopilados para el padre Enrique Flórez como fuentes para la redacción de su obra España Sagrada, tal y como se indica en el primer folio. Transcribimos a continuación el contenido del texto ${ }^{8}$ :

\section{[f. 182r]}

En el Real Monasterio de Arlanza, se hallan cinco tablas, en cuios Marcos se len las coplas siguientes, y estan colocadas en el Claustro Alto al paño del Medio Dia. esta pintada en ellas la vida del señor Conde Fernan Gonzalez

Tabla, o Quadro $1 .^{\circ}$

Encuentro del Conde con los santos Monjes....

obtengan bien podrían arrojar interesantes datos que aclaren las vías de recepción y transmisión de la leyenda a través del ámbito popular lector. En ese sentido, sería interesante comprobar si la refundición del relato en las crónicas breves responde no solo a los códigos del género editorial caballeresco, sino también del género literario. Por otra parte, una edición crítica de la obra de Arredondo nos permitiría comprobar cuáles fueron esos elementos novelescos con los que pretendió atraer la atención del lector de novelas de caballería.

6. Ficha BETA texid 10655 en PhiloBiblon.

7. COLECCION | DE DOCUMENTOS | copiados en la mayor parte | para uso del $\mid$ Rmo. P. Mr. FrHENRIQUE FLOREZ. |. Año de 1798. | Tomo I. [ff. 182r - 182v - 183r]. Signatura: MSS/1622. El manuscrito está digitalizado en la Biblioteca Digital Hispánica $<$ http://bdh.bne.es/bnesearch/detalle/ bdh0000008313>. (Acceso 8 octubre 2017).

8. El texto parece estar escrito por dos copistas: el segundo de ellos, García, rubrica el texto al final. Indicamos en nota al pie cuáles son sus aportaciones. A este respecto, debemos señalar que se trata de anotaciones aclarativas a posteriori, que completan lo ya escrito anteriormente. En su colofón, García indica: "Copie esto el año pasado de 1769. a 10 de julio en el mismo Monasterio de Arlanza i oi dia 14. del mismo mes de este año de 1770 se a trasladado a este papel". No sabemos, entonces, si García se encarga de copiar este documento en dos tiempos, realizando las anotaciones posteriores con una letra más rápida y descuidada, o si el traslado de las descripciones de las tablas al nuevo papel lo realizó otro copista y García añadió sus comentarios y los rubricó, fechando el procedimiento. En todo caso, se trata de notas descriptivas que se realizan en el propio monasterio de Arlanza, a la vista de las tablas, que el propio García visitó, por lo que da a entender. 
Esta es Selva de Abenturas ${ }^{9}$

de los Jabalis seguidos

santos muestran escondidos

en sus cuebas, y espesuras:

Tabla, o Quadro 2.

Martirio de los santos Monjes Pelayo \&ra.

Piensan estos Almanzores,

que venzen siendo tiranos,

y los Muertos á sus manos

son por ellos venzedores.

Tabla, o Quadro $3^{\circ}$

Batalla de Azinas.

Desele divina Gloria,

al Conde, de la de Azinas;

pues son Azañas Divinas

las que le dieron Victoria.

[f. $182 \mathrm{v}$ ]

Tabla, o Quadro $4^{\circ}$

La Rota de Cascajares:

La Rota de Cascajares

es Argumento evidente,

que vale mas poca gente

con Dios, que sin Dios Millares.

\section{Tabla, o Quadro $5^{\circ}$}

Busca el Conde á los Santos Monjes en su Hermita, en donde se le aparezen.

Sus Amigos, y consuelo

Buscaba el Conde en la tierra,

no los hallo ya en la tierra;

pero hallolos en el cielo.

9. Selva de aventuras es el título de la novela bizantina de Jerónimo de Contreras, impresa en Barcelona, en 1565. De existir alguna reminiscencia en el verso hacia este título, ello nos permitiría fijar la composición de la redondilla en una fecha posterior, lo que coincidiría cronológicamente con algunas de las hipótesis de datación moderna de estas coplas que plantearemos más adelante. 
Destas tablas abla, el Dr. Martinez de Cisneros, en su Antiferrera, \& Conferencia III, Pausa V. pagina 127. y 128. Dice son copia deotras antiguas, i creo que las coplas no son antiguas, que estas copias echas despues del año de $1603^{10}$.

\section{[f. 183r]}

En unas tablas, que estan á los lados del Altar del Capitulo de dicho Monasterio de Arlanza, pintadas el año de 1558 por Alfonzo Avulense Monje, se halla el Conde arrodillado á los Pies de los santos Monjes Pelaio \&ra. en una de ellas=Y en la otra esta el Conde con - grillos, en Aczion de ser sacado de la Prision por su Muger Doña Sancha de Nabarra, quien le lleba de la mano. = esta especie dela condesa creo es comenticia: las tablas mencionadas de la vida del Señor Conde, i estas en todas 7, ennumero | aunque echas endistintos tiempos | son de bellas manos ${ }^{11}$.

En Dos urnas de tres quartas cada una de Largo forradas en Brocado de seda + fuerte, y como media vara de Alto de madera estofadas, que estan al Lado del Altar Mayor á la parte del Ebanjelio de la Yglesia del Monasterio de Arlanza hai dos

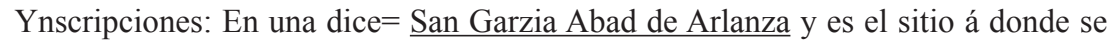
traslado la primera vez desde su Sepulcro, y de esta urna paso á la Arca de Plata, que esta en el Altar de los Santos Martires de Arlanza.= En la otra urna dice= $\underline{\text { Catholico Rey Bamba, }}=$ se Asegura en aquella casa, $+\underline{\underline{u} \text { otra tela mui bistosa }}+12$

\section{[f. 183v]}

esta allí enterrado este gran Rey, y que con sus huesos hai un pergamino moderno, que lo dice. $=$

Del sepulcro del Rey de Bamba trata el mismo Martinez de Cisneros en su antiferreras conferencia 3 Pausa V. pagina 133.

Copie esto el año pasado de 1769. a 10 de julio en el mismo Monasterio de Arlanza i oi dia 14. del mismo mes de este año de 1770 se a trasladado a este papel

Garcia $^{13}$

Tal y como se recoge en el texto, estas coplas procederían de pinturas sobre tabla que se encontrarían en el monasterio de Arlanza y en las que se reproducirían algunos episodios fundamentales de la vida del conde. Dichos episodios provienen de la versión del relato elaborada precisamente en este monasterio: fray Pelayo constituye un elemento argumental puramente arlantino, ya en el Libro de Fernán

10. Este párrafo está escrito por el segundo copista, García.

11. Desde "esta especie" hasta el final del párrafo, está escrito por García.

12. La anotación entre cruces, en el original, está realizada por García.

13. Los dos últimos párrafos están escritos por García. 
González ${ }^{14}$, como respuesta a la versión emilianense en la que San Millán adquiere mayor relevancia en la vida del conde que fray Pelayo y Santiago ${ }^{15}$. Esta tradición arlantina conformará finalmente la versión canónica del relato y la más extendida.

\subsection{Las tablas arlantinas: un recorrido histórico}

A partir del texto conservado en la Biblioteca Nacional, podemos rastrear una serie de menciones adicionales con las que trazar el recorrido de estas tablas. Procederemos a citar estos testimonios.

La ausencia de ediciones críticas de las crónicas de Arredondo dificulta acceder a posibles menciones tempranas a las tablas. En su relato sobre el martirio de los frailes Pelayo, Arsenio y Silvano no da ninguna noticia de las mismas (BNE, mss/2788, ff. 371v-377r). Tampoco aparecen en el relato copiado o refundido por García Moreno: si bien el manuscrito original de 1492 no se ha localizado, en su impresión de 1537 (conservado en la BNE, bajo signatura R/12802) se aprecia que García sigue la versión de la leyenda arlantina contenida en el Libro de Fernán González, caracterizada por el protagonismo individual de fray Pelayo en la fundación del monasterio; la adición de los otros dos monjes parece estar recogida textualmente por primera vez en Arredondo.

14. Empleamos la denominación de la obra propuesta por López Guil (2001) en su edición, en lugar de la canónica de Poema de Fernán González. Consideramos, al igual que López, que a la obra, como texto de clerecía, le corresponde un título identificativo más coherente que la empareje a otros textos elaborados en el mismo circuito monástico, tales como el Libro de Alexandre o el Libro de Apolonio. Véase también el completo estudio de López, contenido en dicha edición, sobre las fuentes por las que se configura la leyenda arlantina, personificada en el fraile Pelayo.

15. En este sentido, véase el estudio de Grande Quejigo (2000) sobre la configuración textual de la leyenda emilianense y la articulación narrativa del episodio de los Votos, que considera refundición tanto de la leyenda de Clavijo (en lo referente a la aparición de Santiago Apóstol en la batalla), de una leyenda local emilianense sobre una victoria bélica de Fernán González y del episodio de los Votos (la victoria cristiana en Simancas, gracias a la aparición de San Millán), registrado en una falsificación documental contenida en el Becerro Galicano de San Millán de la Cogolla. Para Grande, el monasterio de Arlanza no puede ignorar las leyendas que existen en la geografía cercana, y "se introdujo en esta red de leyendas para, sin romper su equilibrio, aprovechar también la figura épica del conde y la misma batalla para promocionar la economía de su monasterio". Ello se debe a que, en esta compleja red de interrelaciones monásticas, "[...] hay dos límites que no pueden sobrepasarse: la negación de las tradiciones asentadas y el esquema fundamental de los hechos. [...] El arlantino añadirá a la serie un tercer personaje [fray Pelayo], pero ha de mantener a su inmediato competidor de la Rioja". Consúltese también el trabajo de Azcárate, Escalona, Jular y Larrañaga (2006), quienes realizan un completo recorrido sobre las manifestaciones textuales (literarias y documentales) con las que los monasterios de Arlanza, San Millán y Silos construyen su identidad, en un intenso "conflicto" por la apropiación de la figura del conde Fernán González. Sobre la historia del monasterio de San Millán de la Cogolla y sus leyendas fundacionales, véase García Turza (2013). 
La indicación más temprana la encontramos en las Historias de Idacio, de Prudencio de Sandoval, quien indica a propósito de su relato del martirio (1634: 310; el original se imprimió por primera vez en 1615): "Hallose este martyrio de los tres santos Monges pintado en los retablos antiguos de la casa. Las tablas y memorias de las reliquias desta casa a pelayo llaman confessor, y si fuera martir tanbien lo dixeran".

En las mismas fechas, Antonio de Yepes (1615: f. 76r), en su Chronica de la Orden de S. Benito, también da cuenta de estas tablas como muestra del martirio:

[...] florecian por estos tiempos en san Pedro de Arlança, san Pelagio, y sus conpañeros san Arsenio, y san Siluano, restauradores de aquel sagrado Conuento, fauorecidos del Conde Fernan Gonçalez. Viuieron estos santos en san Pedro que llaman el viejo, vna ermita que esta encima de san Pedro de Arlança, en donde se vee vn retablo con pinturas antiguas, que muestran como estos santos fueron martirizados [...].

Juan de Arévalo (s. a.), fallecido en 1633, dejó manuscrita una Crónica de los antiguos y primeros reyes y señores de Castilla, en la que da testimonio de lo incuestionable del relato (f. $87 \mathrm{v}$ ):

Y estando la historia del Monge Pelayo, y sus compañeros confirmada con la antigua tradicion del Monasterio de S. Pedro de Arlança, y pintada y labrada enlos retablos de la Iglesia, del modo que la hemos dicho, y los cuerpos destos santos Elevados y puestos en altar, es negocio graue, que ni en aquel santo conuento se huuieran atrevido aponer mano en él, sin mucho fundamento ni los que aora venimos, podemos por solo nuestro antojo, quererlo deribar ni deshaçer.

Será en la obra de Juan de Castro, El glorioso thavmaturgo español, redemptor de cautivo, Santo Domingo de Sylos (1688: 267-270), donde encontremos la primera descripción pormenorizada de los versos y el contenido pictórico de las tablas:

Bolviendo a nuestro valeroso, y esclarecido Conde Fernan Gonçalez, digo, que fueron muchas, y muy señaladas las batallas, y victorias, que consiguiò de los enemigos de la Santa Fè. Algunas estàn escritas en las historias, pero yo quiero hazer aqui memoria de dos insignes, que tuvo en la comarca de Sylos. La vna fue en Cascaxares, y la otra en Azinas, y ambas estàn escritas por extenso en el Archivo de San Pedro de Arlança, y pintadas en vnas tablas muy antiguas del Retablo mayor, que fue de aquel Monasterio. En la de Cascaxares estan estos versos. 


\section{La Rota de Cascaxares \\ Es argumento evidente, \\ Que vale mas poca gente \\ Con Dios, que sin Dios millares.}

De donde se infiere el poder grande que traìa el Moro, y quan pobre de gente se hallava el Conde, pues venciò al enemigo, mas con la ayuda de Dios, que con la de sus Soldados

[...] En la tabla, donde esta pintada la batalla de Azinas, estàn estos versos.

Desele divina gloria

Al Conde de la de Azinas;

Pues son hazañas divinas

Las que le dieron victoria.

[...] Consta esta aparicion de los Santos Monges, de la historia del Monasterio de Arlança, y de vna pintura antiquissima, que oy conserva dicho Monasterio. En ella esta pintada esta aparicion con estos versos Castellanos.

Sus Amigos, y consuelo

Buscava el Conde en la Sierra:

No los hallò ya en la tierra,

Mas hallòlos en el Cielo.

Juan de Ferreras (1716: 284-285) solamente se refiere al relato de fundación del monasterio de Arlanza en términos asépticos y puramente descriptivos. En lo referente a los tres monjes anacoretas, solo indica que "Sus primeros habitadores estàn en aquel Monasterio con grande veneracion"; no hace referencia ni a su martirio, ni a los modos de veneración de estos tres personajes, que sí habían citado historiadores anteriores. No obstante, sí es especialmente crítico con las leyendas arlantinas: sobre Fernán González señala que "[sus] valerosas acciones estàn mezcladas con tantas fabulas, y mentiras, que es muy dificil discernir las verdaderas de las supuestas, y fabulosas [...]" (1716: 315-316). Contra estas refutaciones actuará Diego Martínez de Cisneros, abad del monasterio de Arlanza. En su Anti-Ferreras (1724) responderá al historiador, tratando de legitimar en documentos y tradición la veracidad de los relatos arlantinos. Ello le llevará a realizar un recorrido completo por las reliquias y bienes del monasterio, lo que nos permite acceder hoy a la descripción más completa de las tablas perdidas (1724: 127-129):

Esta misma Historia està esculpida en el Retablo de los Sanctos Martyres, que aunque moderno, se arreglo al mas antiguo de este Monasterio. Tambien està pintada 
en cinco tablas, con gran primor, y como dicen, à lo vivo. Es verdad, que tienen poca antiguedad; porque no passa la pintura de cien años. Pero tambien es cierto, y evidente, que son copias de las primitivas. No sin grave dolor referirè la pèrdida de alhajas tan preciosas. En el libro, que llamamos del Consejo, con toda propriedad (porque en èl se escriven todas las Consultas, y resoluciones) haze tres años, que dì casualmente, inquiriendo otra cosa, con la Acta siguiente:

En diez y siete de Diciembre de este año de mil seiscientos y tres, tuvo nuestro Padre Abbad Consejo, assistiendo à èl su Paternidad, Fray Pelayo de San Benito; el Padre Prior de Casa, fray Andrès Rodriguez; el Padre Prior de Boada, Fray Gonçalo de Guzman; y el Padre Mayordomo Fray Juan Gonçalez. Y lo que se tratò fuè: Que el Señor Don Pedro Fernandez de Mansilla, Oidor de el Consejo de Indias, pedia, y supplicaba à nustro Padre, y à esta Casa, le hiziessen mercer de le dàr los cinco quadros antiguos de la Historia de el Conde; porque le importaba mucho para confirmacion de su Nobleza, y sangre, como quien desciende de el dicho Conde su Señor, y nuestro: los quales pretendia poner por principales alhajas de su Mayorazgo; en cuya recompensa ofrecia, y ofreciò de hazer sacar una copia de ellos de muy buena mano, para que la Casa os gozasse. Y fuera de esto haria va muy buena memoria; porque assi le importaba à su merced, y à sus intentos. Y de presente diò vna muy buena limosna, que fueron veinte escudos en oro para que se gastassen en la Iglesia, ò Sacristia. Y desde luego se applicaron para ayuda de vnos tafetanes, ò tapizes, que sean à proposito para la Capilla de los Martyres. Y todos vinieron en ello, por ser de interès, y provecho para la Casa, tener vn buen amigo, y defensor nuestro, para los pleytos, y negocios de ella. Y lo firmamos. Fecha, vt suprà. Fr. Agustin, Abbad. Fray Gaspar de Burgos, Secretario de el Consejo.

El primero de estos quadros representa à Fernan Gonçalez à la puerta de la Ermita, $\mathrm{y}$ à los tres Anacoretas vestidos de Monges, saludando al Conde. El segundo representa la Rota, ò Batalla de Cascaxares, y la cèlebre Victoria, y lleno el Campo de cadaveres mahometanos. El tercero representa el Martyrio de los tres Anacoretas, à quienes los Moros degollaron no mucho despues, quando se iba edificando el Monasterio. El quarto representa al señor Conde orando puesto de rodillas, y à $\mathrm{S}$. Pelayo en vna nube hablando con èl. Lo mismo que sucediò años despues, muerto yà el Monge Pelayo, algunos dias antes de la famosa Batalla de Acinas: à que concurrieron muchos mas millares de Enemigos, que en la antecedente. Pero fuè la dignacion de Dios igual en este trance; porque embiò à Pelayo, à quien Fernan Gonçalez invocaba por intercessor, à que lo confortasse, y prometiesse la Victoria; porque èl mismo, y San Millàn irian al socorro. El quinto representa la Batalla, y la Victoria, y la apparicion de los dos Sanctos, con vivissima expression.

Ultimamente dexamos probada con medios innegables, y acrysolada la Historia generalmente recibida en nuestra España: Que Fernan Gonçalez Conde Soberano de Castilla fundò, y dotò nuestro Monasterio de Arlança el año de novecientos y doce: y que la ocasion, y causa motiva de esta Fundacion fuè la amistad con los tres Anacoretas, à cuyos meritos, y ruegos debiò el Divino auxilio, en la gravissima presura, antes referida. [...] 
Enrique Flórez, en España sagrada (1772) realizará también una descripción de la historia y bienes del monasterio de Arlanza, empleando para ello los apuntes manuscritos ya mencionados, donde se conservan hoy en día las coplas completas. No obstante, en su trabajo ya impreso realiza una mención parcial a las mismas, limitándose solo a recuperar la copla sobre la batalla de Cascajares:

Así cuenta el suceso [la visita del conde a los tres monjes] la Crónica General en el cap. 17, añadiendo algunas cosas de las que acostumbra, poco firmes: pero la substancia referida consta por documentos del Monasterio, Tablas, y santidad celebrada de los tres Santos Pelayo, Arsenio, y Silvano, de quienes luego hablarémos. La victoria conseguida por el Conde despues del trato con S. Pelayo fue la de Cascajares, (lugar sobre Arlanza, rio arriba, enfrente de las torres de Carazo) cuyo triunfo fue maravilloso, por la poca gente del Conde, y muchedumbre de moros, que se celebró con la memoria siguiente:

La Rota de Cascajares

Es argumento evidente,

Que vale mas poca gente

Con Dios, que sin Dios millares.

Esta batalla y victoria, se pintó con la de Azinas, en unas tablas que huvo en el retablo antiguo del Altar mayor de Arlanza, que después se pusieron en el claustro, donde perseveran copias mas modernas con sus versos, como los referidos de Cascajares. (1772: columnas 96-97)

Su mención resulta interesante principalmente porque en ella realiza un recorrido por las principales menciones historiográficas sobre las tablas y la tradición del monasterio (algunas de las cuales ya hemos indicado anteriormente):

"[Sandoval, sobre el martirio de los tres monjes] Hallóse este martirio de los tres santos Monges pintado en los retablos antiguos da la Casa:" pero despues añade lo arriba referido, de que las memorias de las reliquias de esta casa à Pelayo llaman Confesor, y si fuera Mártir tambien lo digeran: segun cuya adicion parece no se aquietó con las pinturas. Yepes hablando de ellas en el tomo 5. sobre el año 948. dice, que en un retablo de la Ermita de arriba se ven pinturas antiguas, que muestran como estos Santos fueron martirizados, y al punto se remite á lo que de su vida trató en el Tomo I. donde no refirió nada sobre martirio: y asi parece que no halló otro apoyo que estas pinturas, las quales no le obligaron à historiar el martirio ahora, ni antes. (1772: columna 123)

Aun así, concluye que el relato del martirio queda refrendado por tres pruebas: "El martirio le autorizan los documentos referidos del letrero hallado en la urna de San Pelayo, pinturas y tradición firme del Monasterio, y la Bula del Papa Clemente octavo" (1772: columna 130). 
Joaquín Lorenzo Villanueva, en Año christiano de España, (1793: 536), también recoge estas pruebas, y da cuenta del último testimonio que localizamos sobre las tablas:

Lo que hay á favor del martirio de nuestros Santos es: $1^{\circ}$. una memoria que en el arca vieja de sus reliquias se halló en el año 1571, en la qual es llamado San Pelayo Monge y Martir. II $^{\circ}$. El testimonio de Fr. Alonso Chacon que en el libro de los 200. Mártires de Cardeña de que arriba tratamos, impreso en Roma el año 1594, pag 62. dice que el Capitan Zafa martirizó en San Pedro de Arlanza á los Santos Pelagio, Arsenio y Silvano Monges Benedictinos de aquel Monasterio ${ }^{16}$. III $^{\circ}$. Una Bula de Clemente VIII. del año 1604. en que á todos tres llama Mártires. $\mathrm{IV}^{\mathrm{o}}$. Algunas pinturas antiguas que los representan dando la vida en defensa de la fe. $V^{o}$. La tradicion del mismo Monasterio.

Para Amador de los Ríos (1888: 91), un siglo después, las coplas ya no son más que "memoria", sin referirse a las tablas:

[...] Fernán González había ya contraído, como hemos dicho, matrimonio con doña Sancha, y vencido á los musulmanes en Cascajares, triunfo del cual la tradición, en tiempos mucho más cercanos á nosotros, guardó la memoria, como la guarda el Poema escrito en honor del héroe castellano y la consigna la Historia de Arlanza, escrita indudablemente en el siglo XV, tomándolo de la llamada Crónica general, obra del XIII [...]

En nota al pie, consigna:

Flórez, al tratar del referido Monasterio, transcribe la indicada memoria, la cual parece ser ya del siglo XVII ó cuando más del XVI, y dice:

La rota de Cascajares,

es argumento evidente,

que vale más poca gente

con Dios, que sin Dios millares.

16. "Secundam tempore Ferdinandi Gonzalij Castellae Comitis iam senex aduersus quem militauit, \& martyrio affecit in Coenobio sancti Petri ab Arlanza, beatos Pelagium, Arsenium, \& Siluanum, monachos Benedictinos eiusdem Coenobij, sitibundus sanguinis sanctorum, \& Monachis adhuc infensus, saeuitiam, \& immanitatem veterem retinens, vt scelera sceleribus cumulata, grauiori supplicio, \& aeterno lucerentur." (Chacón, 1594: 62-63). Traducción: "Este mismo Zapha, posteriormente, en tiempo de Abderrahmán III y del Conde Fernán González, volvió en otra nueva expedición, y llegando al monasterio de San Pedro de Arlanza, dió muerte a Pelagio, Arsenio y Silvanos, monjes de este monasterio" (Rodríguez y Fernández, 1924: 41). 
[...] Hasta este punto llegaba en la edad moderna la eficacia de la tradición no contradicha. ${ }^{17}$

Cuando posteriormente, en Las ruinas del monasterio de Arlanza (Ríos 1896: 7) describe los restos del lugar, ya no hace referencia a las tablas ni a los versos, salvo para referirse a lo indicado por el padre Flórez (1896: 8). Solo transcribe de nuevo la copla anterior, que acompañaba al cuadro 2 , de nuevo calificada como "memoria":

Obedeciendo a Pelayo [el conde Fernán González], partíase sin más tardar de la ermita, lleno el corazón de lisonjeras esperanzas, é incorporábase á sus gentes, que ya le creían perdido. Dábales cuenta del suceso y de la profecía, y fortalecidos todos con aquella muestra de la predilección divina, trabada la lid con Almoçorre, tan grande fué el triunfo que lograron siendo tan pocos en número los de Castilla, que se celebró con la memoria siguiente: [...]

\subsection{Cuestiones sobre la cronología de las tablas y las coplas}

Los testimonios recopilados dan cuenta de la existencia de un retablo antiguo en el monasterio de Arlanza, parejo a otra serie de pinturas y reliquias con las que el monasterio sostuvo la autenticidad de los relatos de su fundación. Sin embargo, la lectura de tales testimonios dibuja un recorrido histórico complejo en cuanto a las características iconográficas y textuales de las tablas que conformarían dicho retablo. El problema se agrava debido a la pérdida de estas tablas en un momento incierto del siglo XIX, seguramente como consecuencia del proceso de Desamortización que afectó gravemente al monasterio ${ }^{18}$. Se abre, por tanto, un doble interrogante, relativo tanto a la creación de las pinturas y su posible posterior venta, como a la adición de los versos como complemento a las imágenes.

17. Con anterioridad, en 1853, y en una obra encuadrable en el interés romántico por la historia medieval que conduce a viajeros extranjeros hacia España, Louisa Tenison (1853: 368) adscribe estos versos a "one of the chroniclers of [Fernán] González", sin identificarlo, para a continuación transcribirlos. Del mismo modo, en 1873, Vicente de la Fuente (1873: 232) también recoge esta redondilla, relacionándola con el relato de la victoria bélica del conde. No indica su procedencia: ni menciona las tablas, ni propone su origen popular. Mérimée (1903: 121) también recupera estos versos, recibiéndolos como "redondilla populaire".

18. Serrano (1925), abad de Silos, realiza el primer intento de recopilación del cartulario arlantino. Juárez Benítez (2014), en su tesis doctoral dirigida por Escalona Monge, realiza también una revisión del estado de la cuestión sobre el archivo arlantino, y propone una reconstrucción de la colección diplomática del monasterio y de su trayectoria evolutiva. 
Las menciones más tempranas a las tablas se localizan en 1615, en los textos de Sandoval y Yepes. Sin embargo, ninguno hace referencia a la venta de las mismas en 1603, que describió el abad Martínez de Cisneros y posteriormente citó Flórez. Como indicamos anteriormente, no hemos encontrado testimonio ni de las coplas ni de las tablas en la crónica de Arredondo ni en la de García Moreno. Presuponiendo que el acta de venta localizada por Cisneros sea auténtica -no hemos conseguido localizarla, y tal vez la dispersión y pérdida del archivo arlantino dificulte la búsqueda-, ello solo aumenta la confusión, porque el apelativo "muy antiguas" encajaría mejor con unas pinturas lejanas en el tiempo, de procedencia medieval, que Sandoval y Yepes pudiesen conocer. Si la venta y cambio por copias modernas se realizó en 1603, resultaría incoherente que ambos no hiciesen mención en su lugar a las tablas nuevas. Es posible, por otra parte, que ninguno de los dos hubiese visto las pinturas modernas, y por tanto describiesen las antiguas a partir de datos no actualizados que recopilasen; ello explicaría también por qué no aluden a las coplas escritas en ellas.

¿Acaso existieron tablas antiguas, medievales, que fueron vendidas en 1603, tal y como indica el abad Martínez? Y, en caso afirmativo, ¿estarían incluidas en ellas las coplas? La primera mención a las coplas es tardía, por parte de Castro, en 1688, indicando al mismo tiempo que las pinturas son "muy antiguas". Los versos, por otra parte, están escritos en redondillas, esquema estrófico de raíces latinas que comienza a emplearse con mayor incidencia a partir del siglo XIV ${ }^{19}$. Sandoval, en 1615, indicaba que en "las tablas y memoria" de las reliquias de los mártires se denominaba a fray Pelayo como "confessor": tal apelativo no aparece en las coplas que luego describen con más detalle Martínez de Cisneros y Flórez. De haber existido un texto medieval en las hipotéticas tablas originales, se ha perdido.

En todo caso, la ausencia de menciones medievales no implica que no existiesen unas tablas en tal periodo, que luego fuesen sustituidas por copias modernas; ello, independientemente de que los versos fuesen o no una adición

19. No entraremos en cuestiones ortográficas, pues cabe la posibilidad de que quienes han transcrito el contenido de los textos hayan aplicado correcciones conscientes sobre el mismo, atendiendo a la norma que ellos manejan. Es indispensable la consulta de la recientemente publicada Historia de la métrica medieval castellana (Gómez Redondo, 2016). Puede consultarse también el trabajo realizado por Román Gutiérrez (2005) en torno a las apreciaciones teórico-críticas sobre el octosílabo en poéticas y preceptivas de los siglos XVI y XVII. En lo referente a estos versos, las circunstancias de su tardía atestiguación cronológica y algunas características de tono y estilo nos llevan a suponer su procedencia barroca. No obstante, y a falta de pruebas más consistentes, planteamos únicamente esta datación como hipótesis. 
moderna. Apreciamos además un paulatino y progresivo interés historiográfico en el tiempo por recuperar estas tablas y sus textos como pruebas de las leyendas fundacionales del monasterio. Este proceso, característico tanto de las historiografías barroca e ilustrada, no es propio de la mentalidad medieval. El bachiller García Moreno y el abad Gonzalo de Arredondo no precisan de justificar sus relatos, porque ellos mismos asumen la veracidad de los mismos a partir de la legitimidad concedida por la tradición, tanto oral como escrita, que han recibido. Será a través del pasado historiado y escrito como refrendarán definitivamente tal tradición. Sin embargo, a lo largo del siglo XVII el proceso cambia, y derivará en un total cuestionamiento en el siglo XVIII de los textos históricos anteriores. La Historia se interpreta de manera más científica, y las pruebas de tradición, si bien no rechazadas tajantemente, sí tienen que sostenerse sobre testimonios fiables, tanto textuales como pictóricos o arqueológicos. En resumidas cuentas: de haber existido una mención a las supuestas tablas medievales en las obras de García y Arredondo, esta solo hubiese sido anecdótica; en el caso de los textos históricos del XVII que hemos recuperado, por el contrario, toda mención a las tablas constituye una prueba del relato fundacional, que el historiador acredita con su propio testimonio como individuo que ha manejado tal prueba o la ha podido ver. Que Castro describa las pinturas como "muy antiguas" al mismo tiempo que reproduce sus textos resultaría contradictorio, teniendo en cuenta la supuesta venta en 1603: sin embargo, se ajustaría a una reinterpretación de las tablas como pruebas de antigüedad de la leyenda en ellas representada.

Por tanto, la única cronología fehaciente que podemos manejar sobre la existencia tanto de tablas unidas a versos, atendiendo a la documentación recogida, abarca desde 1688 hasta 1793. La coincidencia entre la descripción de las pinturas dada por el abad Martínez y las coplas recogidas en el manuscrito de la BNE avala la existencia de estas tablas en dicho periodo. En lo relativo a los textos, cabe señalar una peculiaridad. Resulta extraño que el abad Martínez de Cisneros no haga ninguna referencia a los textos, pero sí a las pinturas; aun así, ello no anula la existencia de las mismas, que está refrendada por otros autores $\mathrm{y}$, ante todo, por el testimonio que recoge el padre Flórez a partir del manuscrito conservado en la BNE, que da pie a la presente investigación. En cualquier caso, la fecha de 1603 resulta determinante para el recorrido histórico de las tablas: aumenta la confusión sobre su conservación y características, y plantea la posibilidad de que existan dos versiones de las pinturas, cada una con sus propias características iconográficas y textuales. 


\subsection{El "relato" de las tablas}

En las pinturas de Arlanza se reproducen los episodios más importantes de la vida de Fernán González en relación con la fundación del monasterio. El orden de las mismas, atendiendo al desarrollo narrativo de las mismas según la tradición arlantina (recogida en el Libro de Fernán González y las crónicas del abad Arredondo y el bachiller García), no responde a lo expuesto en el manuscrito de la BNE sino a la descripción realizada por el abad Martínez. Por tanto, editamos a continuación el contenido de las coplas tal y como aparece en el citado manuscrito, junto a la descripción de las pinturas a las que acompañan, dada por el $\mathrm{abad}^{20}$.

\section{TABLA 1}

El primero de estos cuadros representa a Fernán González a la puerta de la ermita, y a los tres anacoretas vestidos de monjes, saludando al conde.

Esta es selva de aventuras

de los jabalís seguidos.

Santos muestran escondidos

en sus cuevas y espesuras.

\section{TABLA 2}

El segundo representa la Rota, o Batalla de Cascajares, y la célebre victoria, y lleno el campo de cadáveres mahometanos.

La Rota de Cascajares

es argumento evidente

de que vale más poca gente

con Dios, que sin Dios millares.

\section{TABLA 3}

El tercero representa el martirio de los tres anacoretas, a quienes los moros degollaron no mucho después, cuando se iba edificando el monasterio.

Piensan estos Almanzores que vencen siendo tiranos, y los muertos a sus manos son por ellos vencedores.

TABLA 4

El cuarto representa al señor conde orando puesto de rodillas, y a San Pelayo en una nube hablando con él.

Sus amigos y consuelo

buscaba el conde en la sierra.

20. Actualizamos la ortografía y la puntuación tanto de las descripciones como de las redondillas. 
No los halló ya en la tierra, pero hallólos en el Cielo.

TABLA 5

El quinto representa la batalla, y la victoria, y la aparición de los dos santos, con vivísima expresión.

Désele divina gloria

al conde de la de Hacinas,

pues son hazañas divinas

las que le dieron victoria.

\section{La "tradición" sobre Fernán González: reliquias, pinturas y textos}

Una aproximación científica a las tablas arlantinas plantea múltiples retos. En primer lugar, por la pérdida de las pinturas, tanto en su hipotética primera versión, medieval, como en la segunda, moderna. En segundo lugar, por la propia condición de estas pinturas como texto "multiforma": esto es, un aparato semiótico de signos entrelazados, de tipo tanto lingüístico como iconográfico, engarzados a su vez en una vasta tradición argumental que se plasma en múltiples manifestaciones sígnicas.

El estudio paratextual de estas coplas estará incompleto ante la ausencia de las tablas. No podemos establecer la relación entre texto e imagen, si bien podemos reconstruir el contenido pictórico de dichos paneles a través de la lectura de las coplas y de las descripciones realizadas por parte de quienes pudieron verlos. Martínez sí describe las imágenes, lo que puede orientar nuestro análisis comparado entre dibujo y texto. Igualmente, la conservación del manuscrito de la BNE nos permite conocer todos los textos que las acompañaron, teniendo en cuenta que las referencias históricas a los mismos, que hemos reseñado anteriormente, los recogen solo parcialmente.

La existencia de paneles ilustrados, a la vez que glosados, manifiesta el interés del monasterio de Arlanza por presentar los hechos prodigiosos de su fundador legendario, a través de todas las vías de comunicación posibles, para abarcar a un público heterogéneo, tanto letrado como iletrado. Según el esquema de Panofsky (1939: 3-31; Burke 2005: 45), en lo referente al proceso de interpretación de los tres niveles de significado en toda obra iconográfica, en este caso nos resultaría imposible analizar el primer nivel: la descripción de la pintura y la identificación de sus elementos. Sí podríamos abordar el análisis convencional del segundo nivel, la identificación de las escenas representadas, así como el tercer nivel, de interpretación iconológica, de significados sociales, culturales y religiosos. 
Las pinturas representan los acontecimientos principales del relato de la fundación de Arlanza gracias al conde Fernán González. Siguen un esquema cíclico (figura 1), en el que el martirio de los frailes supone el acontecimiento central:

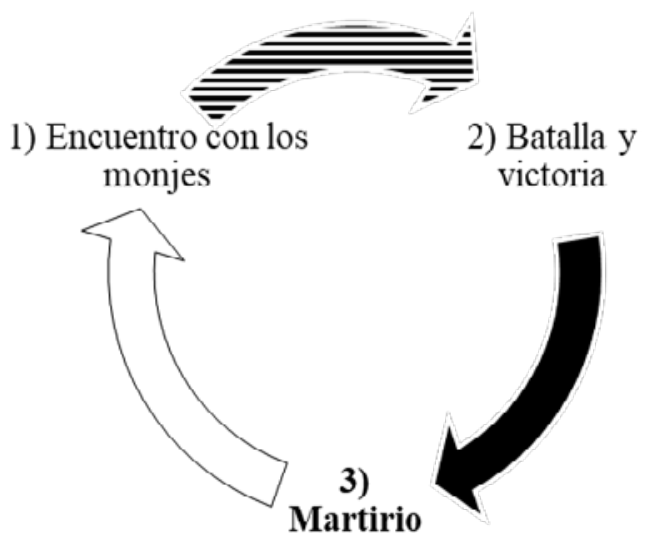

Figura 1. El relato sigue un esquema cíclico tripartito. La flecha negra marca el primer ciclo de encuentro (episodio de la caza del jabali) y posterior victoria en Cascajares, predicha por los monjes. Tras el martirio, acontecimiento central del relato, comienza el segundo ciclo, marcado con flecha blanca: encuentro con los espiritus de los monjes y victoria milagrosa en Hacinas con la aparición de Santiago y San Millán. Nótese cómo se repite el esquema de prospección-victoria (marcado con flecha blanca y negra), de encuentro y batalla.

El desarrollo de los acontecimientos, sin embargo, sigue un esquema de intensificación progresiva. Al primer encuentro, de carácter terrenal, le corresponde otro más elevado, posterior al martirio, de carácter celestial. La primera victoria bélica, en Cascajares, se verá superada en número e importancia por la segunda, en Hacinas, donde el poder celestial también se hará presente mediante la aparición de Santiago y San Millán. De este modo, el episodio del martirio sirve de eje a todo el relato, permitiendo a partir de su consecución la irrupción del poder de Dios en la historia y su intervención directa en las hazañas del conde. Fernán González, además, aparecerá representado con sus dos rasgos de caracterización principales, en relación con el relato arlantino: su carácter piadoso y su valía como guerrero, como fundador del monasterio y defensor de las tierras castellanas. Ello está relacionado con el contenido doctrinal de las coplas: en ellas no solo se resumen los contenidos narrativos implícitos a las imágenes, sino que también se reelaboran para extraer de ellos enseñanzas moralizantes. "Vale más poca gente / con Dios, que sin Dios milla- 
res" y "Pues son hazañas divinas / las que le dieron victoria", versos de las tablas 2 y 5 , respectivamente, ejemplifican la intercesión divina en el proceso de guerra contra los infieles; "y los muertos a sus manos / son por ellos vencedores" y "No los halló ya en la tierra / pero hallólos en el Cielo", versos de las tablas 3 y 4 , inciden en la vida eterna como verdad de fe, y su consecución por medio del martirio. De este modo, las redondillas funcionan como textos descriptivos de los episodios en ellos contenidos y representados por las imágenes, y como textos argumentativos, que plantean una interpretación devota de tales sucesos.

La imagen constituye un fuerte ejemplo de condensación de relatos complejos en una simple instantánea, a la que la estrofa añade una interpretación adicional complementaria. Como ya hemos señalado, estas imágenes y sus coplas remiten al relato de las hazañas del conde elaborado en el ámbito arlantino. Por ello, la percepción de los significados implícitos a las pinturas está limitada a quienes conozcan tal relato y sepan extraer de él todo su contenido piadoso e identitario; esto es, manejen el lenguaje con el que se codifican los contenidos del segundo y tercer nivel iconográfico. En consecuencia, su dependencia con la tradición arlantina es total. "Tradición" entendida en un sentido amplio, que abarque todo tipo de representaciones textuales, pictóricas y arqueológicas a las que se les atribuyan unos contenidos ficcionales con apariencia de verismo histórico. Un relato perpetuado a lo largo del tiempo y transmitido por canales de configuración autorizados de tipo monástico. De este modo, se asienta una tradición multiforme, un cúmulo de manifestaciones remitentes a una narración común a la que dotan de verosimilitud al mismo tiempo que se cargan de los significados que ella les otorga. Estas tablas, en definitiva, se valen tanto de la tradición, que les da sentido, como al mismo tiempo sirven de recordatorio de la misma al público -y, en cierto modo, de su constatación como hecho histórico, refrendado por otros materiales de dicha tradición-.

El monasterio de Arlanza, por tanto, construye las pruebas de su historia no solo a través de la literatura. Esta es solo una de las muchas muestras de la tradición: el origen de Arlanza se transmite en un complejo aparato de testimonios interconectados, a los que pertenecen estas tablas y sus coplas, las crónicas de Arredondo y García, los documentos administrativos, las reliquias de los tres frailes mártires, otras pinturas del monasterio, etc. Todas ellas parten de un sustrato común al que dan forma palpable. Son, por otra parte, elementos que calan en los fieles, aunque con el tiempo se verán despojados de buena parte de sus contenidos propagandísticos, como podemos comprobar en la pervivencia 
de la copla de Cascajares en el ámbito popular, una vez desaparecen las tablas ${ }^{21}$. La tradición solo puede pervivir en un entorno de recepción, reformulación y reproducción óptimo, donde se presuponga su veracidad y, por tanto, en el que pueda demostrar su relevancia como fuente histórica.

\section{Conclusiones}

La configuración de la leyenda de Fernán González, tanto en lo referente a la caracterización del personaje como al desarrollo narrativo de sus hazañas, no se limita exclusivamente a la producción escrita, tanto literaria como historiográfica. La tradición sobre el personaje se asienta en una narrativa compleja, manifestada en múltiples formatos y códigos de interpretación, remitentes todos a un contenido común: la relevancia del monasterio como foco de escritura de la historia.

La existencia de las coplas y su recepción por parte de visitantes al monasterio revela diferentes modos de concepción de la historia a lo largo del tiempo. La datación de las mismas, por otra parte, es compleja, lo que se agrava debido a su pérdida en una fecha indeterminada: solo podemos situarlas con cierta seguridad a partir de 1688, fecha de su primera transcripción parcial. Ello coincide con una polémica historiográfica acerca de la veracidad de las leyendas del monasterio: veracidad que quedaría demostrada, según los cronistas de la época, en pruebas materiales tales como documentos, reliquias y las tablas. Las redondillas incluidas en ellas, por tanto, cumplirían una función propagandística dentro de un aparato de códigos combinados, por los que el pasado glorioso del monasterio se ve continuamente recuperado, recordado y, finalmente, actualizado. En las tablas, elaboradas probablemente en el siglo XVII, se plasman los acontecimientos principales de la leyenda arlantina: las victorias milagrosas del conde y el martirio de los monjes fundadores. Ello refleja un proceso de simplificación del relato para concentrarlo en sus principales elementos significativos, de cara a su difusión pública. Las coplas completarían este proceso, mediante una reformulación en clave doctrinal y tipología argumentativa de los contenidos narrativos adscritos a las imágenes: sobre los episodios representados se extraen conclusiones de tipo moral, que sir-

21. Como vimos, en 1688 recoge Arévalo el contenido de esta estrofa, que dos siglos después perdurará, según Amador de los Ríos, en la memoria popular. Cabe preguntarse si la copla, por tanto, se escribe a partir de una tradición oral, o esta tradición oral deriva a partir de la composición de una copla escrita: esta misma cuestión podría aplicarse también al resto de estrofas. 
ven para promover en los fieles lectores $^{22}$ la creencia en la vida eterna a través del martirio y la veracidad de la intercesión de Dios en la historia militar del pasado.

Todo ello aparece engarzado en una tradición bien asentada en otras tantas fuentes, sin la cual este retablo no tendría sentido: los episodios reformulados tanto en las pinturas como en las coplas remiten a relatos completos que el público receptor debía conocer previamente, para así extraer todos los significados adicionales propuestos en los versos. Esta tradición conecta con una narración subyacente, perpetuada desde mediados del siglo XIII en múltiples manifestaciones literarias donde el pasado legendario adquiere legitimidad histórica gracias a su plasmación escrita. El Libro de Fernán González, sin duda empleado como texto en la predicación, y las crónicas del abad Gonzalo de Arredondo y el bachiller García Moreno son las aportaciones más relevantes en este panorama, y su estudio pormenorizado en relación con este retablo aún está pendiente. Ante la ausencia de las tablas y sus redondillas, los objetivos de este estudio quedan limitados a la recuperación de las mismas a partir de testimonios secundarios, y a establecer propuestas de estudio en relación con la tradición arlantina en toda su extensión. La reconstrucción de los textos aquí ofrecida supone un primer paso en ese sentido, a la espera de próximas aportaciones multidisciplinares (en el plano de la filología, la historia o el arte) que nos permitan recuperar el patrimonio del monasterio de San Pedro de Arlanza, pieza clave para la construcción historiográfica e identitaria de Castilla.

\section{Bibliografía}

ARÉVALO, J. de (s. a.). Crónica de los antiguos y primeros reyes y señores de Castilla, en la que da testimonio de lo incuestionable del relato. Biblioteca Nacional de España. Mss/1282.

AZCÁRATE, P. et al. (2006). "Volver a nacer: historia e identidad en los monasterios de Arlanza, San Millán y Silos (siglos XII-XIII)". Cahiers d'Études Hispaniques Médiévales 29: 359-394.

22. Debemos tener también en cuenta el profundo carácter oral de la transmisión de la leyenda arlantina, ya desde sus primeras manifestaciones monacales. El Libro de Fernán González presenta rasgos textuales que evidenciarían su uso como lectura pública en el monasterio (véase Lopez Guil 2001: 77-88, como introducción a este respecto), ante fieles peregrinos que visitasen el sepulcro del conde. A través de estos relatos, se asentaría el relato fundacional del lugar de forma comunitaria. Las tablas servirían igualmente como potente soporte visual para la historia narrada. Con la misma finalidad, como ya indicamos, compone fray Gonzalo de Arredondo sus obras a finales del siglo XV. 
BURKE, P. (2005). Visto y no visto. El uso de la imagen como documento histórico. Traducción de Teófilo de Lozoya. $1^{\text {a }}$ edición en Biblioteca de Bolsillo. Barcelona: Crítica.

CASTRO, J. de (1688). El glorioso thavmatvrgo español, redemptor de cautivos, Santo Domingo de Sylos. Madrid: Imprenta de Melchor Álvarez.

CHACÓN, A. (1594). De martyrio dvcentorvm monachorvm S. Petri a Cardegna Ordinis S. Benedicti Hispaniarum Burgensis dioecesis. Roma: Imprenta de Bartolomé Bonfadini.

CORFIS, I. A. (2011). "La estoria del noble cauallero el conde Fernan Gonzalez con la muerte de los siete infantes de Lara". Tirant 14: 5-46.

CORREA CALDERÓN, E. (1964). La leyenda de Fernán González (Ciclo poético del conde castellano). $2^{\mathrm{a}}$ edición. Madrid: Aguilar.

COTRAIT, R. (1969). "Pour une bibliographie de Fernán González. A propos d'une oeuvre conjecturale introuvée de Blasco Ibáñez et d'une autre de Fernández y González redécouverte". Bulletin Hispanique 71 (3-4): 591-603.

COTRAIT, R. (1970). "Pour une bibliographie de Fernán González. II. Une Comedia nueva anonyme de 1797: La conquista de Madrid por el Rey Don Ramiro y Conde Fernán González". Bulletin Hispanique 72 (3-4): 346-359.

COTRAIT, R. (1973a). "Pour une bibliographie de Fernán González. III : Un passage oublié du David perseguido y Alivio de Lastimados du Doctor Cristóbal Lozano, suivi de remarques sur le livre de Samuel, source possible d'un épisode de la légende de Fernán González". Bulletin Hispanique 75 (3-4): 359-382.

COTRAIT, R. (1973b). "Por une bibliographie de Fernán González. Une Comedia Nueva de Manuel Bellosartes, La fuerza del amor conyugal o Sancha, Condesa de Castilla". Bulletin Hispanique 75 (3-4): 383-410.

ESCALANTE VARONA, A. (2016). "Tratamiento literario de la figura de Fernán González: fuentes primarias y ediciones". Boletín de la Institución Fernán González 95 (252): 97-116.

FERRERAS, J. de (1716). Historia de España. Volumen IV. Madrid: Imprenta de Francisco del Hierro.

FLÓREZ, E. (1772). España Sagrada. Theatro geographico-historico de la iglesia de España. Tomo XXVII. Madrid: Imprenta de D. Antonio de Sancha.

FUENTE, V. de la (1873). Historia eclesiástica de España. Tomo III, edición corregida y aumentada. Madrid: Compañía de impresores y libreros del reino.

GARCÍA TURZA, F. J. (2013). El Monasterio de San Millán de La Cogolla: una historia de santos, copistas, canteros y monjes. León: Everest. 
GÓMEZ PÉREZ, J. (1959). "Una crónica de Fernán González escrita por orden del emperador Carlos V". Revista de Archivos, Bibliotecas y Museos 64 (2): 551-581.

GÓMEZ REDONDO, F. (2007). Historia de la prosa medieval castellana. IV, El reinado de Enrique IV: el final de la Edad Media. Conclusiones. Guía de lectura. Apéndices. Índices. Madrid: Cátedra.

GÓMEZ REDONDO, F. (Coord.) (2016). Historia de la métrica medieval castellana. Logroño: Cilengua.

GRANDE QUEJIGO, F. J. (1991). "Ramón Menéndez Pidal y la leyenda de Fernán González en sus versiones medievales" en $R$. Menéndez Pidal, $R$. Otero Pedrayo. Simposio celebrado en Madrid: Actas. (Ed. M. Mourelle de Lema). A Coruña: Ed. Do Castro: 43-61.

GRANDE QUEJIGO, F. J. (2000). Hagiografia y difusión en la "Vida de San Millán de la Cogolla” de Gonzalo de Berceo. Logroño: Instituto de Estudios Riojanos <http://www.vallenajerilla.com/berceo/grandequeijo/tradicionesmedievales.htm $>$ (Acceso 9 octubre 2017).

JUÁREZ BENÍTEZ, P. (2014). La colección diplomática del monasterio de San Pedro de Arlanza. Formación y trayectoria evolutiva. Tesis doctoral dirigida por Julio Escalona Monge. Universidad Complutense de Madrid.

LÓPEZ GUIL, I. (2001). Libro de Fernán Gonçález. Madrid: CSIC.

MARTÍNEZ DE CISNEROS, D. (1724). Anti-Ferreras, desagravios de Fernan Gonzalez, conde soberano de Castilla, y fundador de el monasterio de San Pedro de Arlança Benedictino. Madrid: Oficina de Lorenzo Francisco Mojados.

MENÉNDEZ PIDAL, M. (1896). La leyenda de los Infantes de Lara. Madrid: Hijos de José M. Ducazcal.

MÉRIMÉE, E. (1903). “Une excursion au pays des épopées”. Bulletin Hispanique 5 (2): 113-139.

PANOFSKY, E. (1939). Studies in Iconology. Humanistic themes in the art of the Renaissance. Nueva York: Oxford University Press.

PÉREZ PRIEGO, M. Á. (1989). “Actualizaciones literarias de la leyenda de Fernán González" en La leyenda. Antropología, historia, literatura. Actas del coloquio celebrado en la casa de Velázquez. (Coord. J.-P. Étienvre). Madrid: Universidad Complutense de Madrid/Casa Velázquez: 238-252.

RÍOS, A. de los (1888). España. Sus monumentos y artes. Su naturaleza e historia. Barcelona: Establecimiento Tipográfico-Editorial de Daniel Cortezo y Compañía.

RÍOS, A. de los (1896). Las ruinas del monasterio de Arlanza. Madrid: Imprenta de los Hijos de M. G. Hernández. 
RODRÍGUEZ Y FERNÁNDEZ, I. (1924). Los doscientos mártires de Cardeña. Recuerdos y crítica. Madrid: Imprenta de la viuda de López del Horno.

ROMÁN GUTIÉRREZ, I. (2005). "La poética del octosílabo en tratados y preceptivas" en En torno al canon, aproximaciones y estrategias: VII Encuentro Internacional sobre Poesía del Siglo de Oro. (Coord. por Begoña López Bueno). Sevilla: Universidad de Sevilla: 167-196.

SANDOVAL, P. de (1634). Historias de Idacio obispo que escrivio poco antes que España se perdiese [...]. Pamplona: Imprenta de Nicolas de Asiaín.

SERRANO, L. (1925). Cartulario de San Pedro de Arlanza, antiguo monasterio benedictino. Madrid: Junta para la Ampliación de Estudios e Investigaciones Científicas.

TENISON, L. (1853). Castile and Andalucia. Londres: Richard Bentley.

TOSCANO, N. (1980). "Edición crítica de los versos inéditos de Arredondo sobre Fernán González [1]". Boletín de la Institución Fernán González 195: 273-326.

TOSCANO, N. (1981a). "Edición crítica de los versos inéditos de Arredondo sobre Fernán González [2]”. Boletín de la Institución Fernán González 196: $53-110$.

TOSCANO, N. (1981b). "Edición crítica de los versos inéditos de Arredondo sobre Fernán González [3]". Boletín de la Institución Fernán González 197: 321-360.

TOSCANO, N. (1981). "Los versos inéditos de la Crónica Arlantina de Fray Gonzalo de Arredondo". Boletín de la Institución Fernán González 199: 317-339.

VAQUERO, M. (1987). Vida Rimada de Fernán González. Exeter: Universidad de Exeter.

VAQUERO, M. (2003). "La crónica del Cid y la crónica de Fernán González entre editores, copistas e impresores, 1498-1514". Romance philology 57 (1): 89-103.

VILlANUEVA, J. L. (1793). Año christiano de España. Tomo VIII. Madrid: Imprenta Real.

YEPES, A. de (1615). Coronica general de la Orden de San Benito, Patriarca de Religiosos. Tomo V. Valladolid: Francisco Fernández de Córdoba. 